\title{
SISTEM PAKAR HUKUM PIDANA PENCURIAN MENGGUNAKAN ALGORITMAFUZZY DECISION TABLE BERBASIS ANDROID
}

\author{
Agung Wibowo ${ }^{1}$, Rival Afrian², Saeful Bahri ${ }^{3}$ \\ ${ }^{1,2}$ STMIK Nusa Mandiri Sukabumi \\ ${ }^{3}$ STMIK Nusa Mandiri Jakarta \\ ${ }^{1.2} \mathrm{Jl}$. Veteran II No.20A Kota Sukabumi, 43111, Indonesia \\ ${ }^{3} \mathrm{Jl}$. Kramat Raya No. 25 Senen, Jakarta, 10450, Indonesia \\ agung.awo@nusamandiri.ac.id
}

\begin{abstract}
Abstrak- Hukum pidana yang komplek sulit dimengerti orang awam dalam memilah pasal-pasal yang mengaturnya, untuk lebih mempermudah masyrakat dalam mengerti dan memilah tentang pasal-pasal yang digunakan untuk menjerat pelaku hukum pidana, pada peneitian ini akan encoba menerapkan sebuah algoritma yang mengelompokan dan menentukan kadar dari sebuah tinggkat kejahatan yang dilakukan dalam hal ini algoritma yang kami gunakan yaitu fuzzy decision tree yang telah terbukti cocok untuk kasus yang yang mempunyai nilai abu-abu,algoritma ini kami gunakan untuk untuk menentukan perundangan mana yang yang cocokdisangkakan kepada pelaku pidana, pada penelitian ini kami hanya melakukan penelitian pada tindak pidana pidana materiil, terutama kasus pencurian, agar lebih mempermudah dalam penggunaan kami menerapkan rule-rule hasil perhitungan dari defuzifikasinya kedalam decision tree selanjutnya kami terapkan kedalam sebuah aplikasi berbasis mobile android.
\end{abstract}

Keywords- Fuzzy decison tree, Pidana materiil, Android

\begin{abstract}
The complex criminal law is difficult for a layman to understand in sorting out the articles that govern it, to better facilitate the society in understanding and sorting about the articles used to ensnare criminal offenders, in this study it will be experimented with an algorithm that classifies and determines the level of a high crime committed in this case the algorithm we use is a fuzzy decision tree that has proven to be suitable for cases that have a gray value, this algorithm we use to determine which legislation is suitable to be suspected to criminals, in this study we just doing research on criminal matters, especially the case of theft, in order to make it easier in our use apply rule-rule calculation results from defuzification for decision tree then we apply into an android mobile-based applications.
\end{abstract}

Keywords - Fuzzy Decison Tree, Material Criminal, Android

\section{PENDAHULUAN}

Masalah hukum pidana yang komplek, sulit bagi orang awam untuk mengerti dan memilah pasal-pasal yang mengatur suatu kasus hukum. Belum lagi ketidakmengertian tentang hukum menyebabkan faktor kebingungan bagi masyarakat awam saat terlibat dalam suatu kasus pidana, baik sebagai tersangka, korban, maupun sebagai pihak keluarga dari tersangka [1], [2], [3]. Hukum pidana adalah keseluruhan peraturan hukum yang mengatur atau menerangkan perbuatan mana yang merupakan kejahatan atau pelanggaran, serta hukuman mana yang dapat dijatuhkan oleh karena kejahatan atau pelanggaran tersebut. Hukum pidana terbagi menjadi dua bagian yaitu hukum pidana materiil dan hukum pidana formil [4].

Laporan Tahunan Krimsus Sat Reskrim dan Laporan Akuntabilitas Kinerja Aparatur Instansi Pemerintah (LAKIP), data kasus atau perkara yang terjadi di wilayah hukum polres Sukabumi kota selama dua tahun penelitian, pada tahun 2012 prosentase tindak pidana materiil $75 \%$ dan sisa nya tindak pidana formil. Tahun 2013 tindak pidana materiil meningkat menjadi $84 \%$ dan tindak pidana formil turun menjadi $16 \%$ [4] [5].

Penerapan ilmu komputer semakin meluas ke berbagai bidang, penerapan ilmu komputer khususnya dibidang hukum sudah banyak berkembang. Sistem pakar yang merupakan salah satu cabang ilmu komputer juga dapat diterapkan dibidang ilmu hukum pidana materiil [6]. Sistem pakar merupakan program yang mampu menyimpan pengetahuan dan kaidah dari domain pakar yang khusus. Sistem pakar dapat membantu seorang yang awam atau tidak ahli dalam suatu bidang tertentu akan dapat menjawab pertanyaan, menyelesaikan masalah dan mengambil keputusan yang biasanya dilakukan oleh seorang pakar [7], [8], [9]. 
Penelitian ini menerapkan fuzzy logic di bidang hukum pidana materiil, terutama kasus pencurian sesuai kitab undang-undang yang berlaku dengan menggunakan konsep sistem pakar yang diimplementasikan kedalam aplikasi android dengan studi kasus di Kota Sukabumi. Sistem pakar yang merupakan suatu sistem berupa software dimana mesin dalam hal ini handphone bersistem operasi android dibuat seakan-akan berpikir seperti seorang pakar atau ahli dalam bidangnya, khususnya untuk menangani hukum pidana materiil [6] [10].

\section{Metodologi PENELITIAN}

Metode penelitian pada sistem pakar berbasis android ini menggunakan fuzzy logic, yaitu suatu cara yang tepat untuk memetakan suatu ruang input kedalam suatu ruang output yang mempunyai nilai kontinyu. Fuzzy dinyatakan dalam derajat (parameter) dari suatu keanggotaan dan derajat kebenaran, oleh sebab itu sesuatu dapat dikatakan sebagai benar dan sebagian salah satu pada waktu yang sama [11]. Salah satu solusi untuk menangani masalah ini dengan membuat aplikasi sistem pakar hukum pidana materil dengan fuzzy logic yang diimplementasikan pada sistem operasi android, untuk mempermudah masyarakat mendapatkan informasi dan solusi untuk mengatasi tindak pidana materiil.

Penelitian dilakukan melibatkan wawancara di bagian Yanmas Sat Reskrim, Subbag Hukum bag. Sumda dan Lembaga Hukum Kejaksanaan Negeri Kota Sukabumi serta dengan mempelajari laporan kasus tindak pidana pada sat reskrim polres kota sukabumi tahun 2012-2013.

\section{A. Fuzzy Decision Table}

Tabel Keputusan adalah tabel yang digunakan sebagai alat bantu untuk menyelesaikan logika di dalam program [13] .Tabel keputusan terdiri dari empat bagian utama (lihat Gbr 1), yaitu: Condition Set/Stub, Condition Space/Entry, Action Set/Stub dan Action Set/Stub. Pada tabel keputusan tradisional, Condition set memuat kondisi yang relevan atau atribut (masukan, premis atau sebab) yang mempengaruhi proses pengambilan keputusan. Condition Space berisi kombinasi kemungkinan kondisi dari pernyataan pada condition set.Action set memuat semua kemungkinan aksi (keluaran, konklusi atau konsekuensi) yang dapat dipilih oleh pengambil keputusan. Action space memuat katagori dari seluruh kemungkinan aksi dari action set [14]. Secara tradisional, tabel keputusan (DT), menunjukkan bahwa kondisinya ditentukan secara tepat. Masalah potensial dari DT tersebut adalah bahwa kesalahan pengukuran tidakdiperhitungkan. Fuzzy Decision Table (FDT) menawarkan solusi untuk masalah ini dengan memanfaatkan logika fuzzy pada tabel keputusan [15], [14].

\begin{tabular}{|c|c|}
\hline Problem area & \\
\hline CONDITION SET & CONDITION SPACE \\
\hline ACTION SET & ACTION SPACE \\
\hline
\end{tabular}

Gbr. 1Tabel Keputusan

\section{HASIL DAN PEMBAHASAN}

Rancangan mesin inferensi Fuzzy untuk menentukan himpunan fuzzy dari setiap variabel, dimana pada penelitian ini variabel yang digunakan adalah hasil pemeriksaan catatan kepolisian terhadap tindak pidana materiil yang akan digunakan sebagai masukan dari mesin inferensi fuzzy. Error! Reference source not found. memaparkan batasan variabel dan himpunan fuzzy yang akan digunakan pada aplikasi.

TABEL I

VARIABEL DAN HIMPUNAN FUZZY

\begin{tabular}{|l|l|l|l|}
\hline \multirow{2}{*}{ Variabel Fuzzy } & \multicolumn{3}{|c|}{ Himpunan Fuzzy } \\
\cline { 2 - 4 } & $\begin{array}{c}\text { Ringan } \\
(\mathbf{R})\end{array}$ & \multicolumn{1}{|c|}{$\begin{array}{c}\text { Sedang } \\
(\mathbf{S})\end{array}$} & $\begin{array}{c}\text { Tinggi } \\
(\mathbf{T})\end{array}$ \\
\hline $\begin{array}{l}\text { Nilai Barang dicuri } \\
(\mathrm{BC})\end{array}$ & $\leq 5$ & $5 \leq \mathrm{BC} \leq 75$ & $\geq 75$ \\
\hline Banyak Pelaku (PP) & $\leq 1$ & $1 \leq \mathrm{PP} \leq 5$ & $\geq 5$ \\
\hline $\begin{array}{l}\text { Tingkat Ancaman } \\
\text { (ANC) }\end{array}$ & $\leq 25$ & $\begin{array}{l}25 \leq \mathrm{ANC} \leq \\
85\end{array}$ & $\geq 85$ \\
\hline $\begin{array}{l}\text { Tingkat Penipuan } \\
\text { (PNP) }\end{array}$ & $\leq 15$ & $\begin{array}{l}15 \leq \mathrm{PNP} \\
\leq 55\end{array}$ & $\geq 55$ \\
\hline $\begin{array}{l}\text { Tingkat Kerusakan } \\
\text { (KRS) }\end{array}$ & $\leq 10$ & $10 \leq \mathrm{KRS} \leq 60$ & $\geq 60$ \\
\hline $\begin{array}{l}\text { Tingkat Kekerasan } \\
\text { (KER) }\end{array}$ & $\leq 25$ & $25 \leq \mathrm{KER} \leq 75$ & $\geq 75$ \\
\hline
\end{tabular}

Himpunan Fuzzy pada Error! Reference

source not found. dapat diterjemahkan kedalam bentuk persamaan kurva. Kurva himpunan untuk variabel BC dapat dilihat pada persamaan rumus 1-3, variabel PP dapat dilihat pada 4-6, variabel ANC lihat rumus 7-9, varibel PNP lihat rumus 10-12 variabel KRS persamaan rumus 13-15 dan variabel KER persamaan rumus 15-18.

$$
\begin{gathered}
\text { Variabel Barang dicuri }(\mathrm{BC}) \\
\mu \text { Ringan }[x]\left\{\begin{array}{c}
1 ; x \leq 5 \\
\frac{(x-15)}{10} ; 5 \leq x \leq 15 \\
0 ; x \geq 15
\end{array}\right. \\
\mu \text { Sedang }[x]\left\{\begin{array}{c}
0 ; x \leq 15 \\
\frac{(x-15)}{10} ; 5 \leq x \leq 15 \\
1 ; 15 \leq x \leq 75 \\
\frac{(85-x)}{10} ; 75 \leq x \leq 85 \\
0 ; x \geq 85
\end{array}\right.
\end{gathered}
$$


$\mu$ Ting $i[x]\left\{\begin{array}{c}0 ; x \leq 75 \\ \frac{(x-85)}{10} ; 75 \leq x \leq 85 . \\ 1 ; x \geq 85\end{array}\right.$

Variabel Pelaku Pencurian (PP)

$\mu \operatorname{Ringan}[x]\left\{\begin{array}{c}1 ; x \leq 1 \\ 2-x ; 1 \leq x \leq 2 \\ 0 ; x \geq 2\end{array}\right.$

$\mu$ Sedang $[x]\left\{\begin{array}{c}0 ; x \leq 1 \\ x-2 ; 1 \leq x \leq 2 \\ 1 ; 2 \leq x \leq 5 \\ 6-x ; 5 \leq x \leq 6 \\ 0 ; x \geq 6\end{array}\right.$

$\mu$ Tinggi $[x]\left\{\begin{aligned} 0 ; x & \leq 5 \\ x-6 ; 5 & \leq x \leq 6 \\ 1 ; x & \geq 6\end{aligned}\right.$

Variabel Tingkat Ancaman (ANC)

$\mu \operatorname{Ringan}[x]\left\{\begin{array}{c}1 ; x \leq 25 \\ \frac{(x-35)}{10} ; 25 \leq x \leq 35 \\ 0 ; x \geq 35\end{array}\right.$

$\mu$ Sedang $[x]\left\{\begin{array}{c}0 ; x \leq 25 \\ \frac{(x-35)}{10} ; 25 \leq x \leq 35 \\ 1 ; 35 \leq x \leq 85 \\ \frac{(95-x)}{10} ; 85 \leq x \leq 95 \\ 0 ; x \geq 95\end{array}\right.$

$\mu$ Tinggi $[x]\left\{\begin{array}{c}0 ; x \leq 85 \\ \frac{(x-95)}{10} ; 85 \leq x \leq 95 \\ 1 ; x \geq 95\end{array}\right.$

Variabel Tingkat Penipuan (PNP)

$\mu \operatorname{Ringan}[x]\left\{\begin{array}{c}1 ; x \leq 15 \\ \frac{(25-x)}{10} ; 15 \leq x \leq 25 . \\ 0 ; x \geq 25\end{array}\right.$
$\mu$ Sedang $[x]\left\{\begin{array}{c}0 ; x \leq 15 \\ \frac{(x-25)}{10} ; 15 \leq x \leq 25 \\ 1 ; 25 \leq x \leq 55 \\ \frac{(x-65)}{10} ; 55 \leq x \leq 65 \\ 0 ; x \geq 65\end{array}\right.$ $\mu \operatorname{Rendah}[x]\left\{\begin{array}{c}0 ; x \leq 55 \\ \frac{(x-65)}{10} ; 55 \leq x \leq 65 \\ 1 ; x \geq 65\end{array}\right.$

Variabel Tingkat Kerusakan (KRS)

$\mu \operatorname{Ringan}[x]\left\{\begin{array}{c}1 ; x \leq 10 \\ \frac{(20-x)}{10} ; 10 \leq x \leq 20 \\ 0 ; x \geq 20\end{array}\right.$

$\mu$ Sedang $[x]\left\{\begin{array}{c}0 ; x \leq 10 \\ \frac{(x-20)}{10} ; 10 \leq x \leq 20 \\ 1 ; 20 \leq x \leq 60 \\ \frac{(70-x)}{10} ; 60 \leq x \leq 70 \\ 0 ; x \geq 70\end{array}\right.$

$\mu$ Tinggi $i x]\left\{\begin{array}{c}0 ; x \leq 60 \\ \frac{(x-70)}{10} ; 60 \leq x \leq 70 . \\ 1 ; x \geq 70\end{array}\right.$

Variabel Tingkat Kekerasan (KER)

$\mu \operatorname{Ringan}[x]\left\{\begin{array}{c}1 ; x \leq 25 \\ \frac{(35-x)}{10} ; 25 \leq x \leq 35 \\ 0 ; x \geq 35\end{array}\right.$

$\mu$ Sedang $[x]\left\{\begin{array}{c}0 ; x \leq 25 \\ \frac{(x-35)}{10} ; 25 \leq x \leq 35 \\ 1 ; 35 \leq x \leq 75 \\ \frac{(85-x)}{10} ; 75 \leq x \leq 85 \\ 0 ; x \geq 85\end{array}\right.$

$\mu$ Tinggi $[x]\left\{\begin{array}{c}0 ; x \leq 60 \\ \frac{(x-70)}{10} ; 60 \leq x \leq 70 \\ 1 ; x \geq 70\end{array}\right.$

Pada penelitian ini FDT pidana materil direpresentasikan kedalam bentuk tabel II.

TABEL II

REPRESNTASI FDT HUKUM PIDANA PENCURIAN

\begin{tabular}{|c|c|}
\hline Action Set & \begin{tabular}{|l} 
Pasal Pidana \\
\\
\end{tabular} \\
\hline $\begin{array}{l}\text { Variabel Pidana } \\
\text { (BC, PP, ANC, PNP, KRS, } \\
\text { KER) }\end{array}$ & $\begin{array}{l}\text { otaan Fuzzy } \\
\text { Condition Space }\end{array}$ \\
\hline
\end{tabular}


TABELIII

FDT HUKUM PIDANA MATERIIL

\begin{tabular}{|c||c|c|c|c|c|c|c|c|l|l|}
\hline $\begin{array}{c}\text { Tuntuta } \\
\text { n }\end{array}$ & $\begin{array}{c}\mathbf{3 6} \\
\mathbf{4}\end{array}$ & $\begin{array}{c}\mathbf{3 6} \\
\mathbf{8}\end{array}$ & $\begin{array}{c}\mathbf{3 7} \\
\mathbf{3}\end{array}$ & $\begin{array}{c}\mathbf{3 7} \\
\mathbf{9}\end{array}$ & $\begin{array}{c}\mathbf{3 6 7} \\
\mathbf{1}\end{array}$ & $\begin{array}{c}\mathbf{3 6 7} \\
\mathbf{2}\end{array}$ & $\begin{array}{c}\mathbf{4 8} \\
\mathbf{2}\end{array}$ & $\begin{array}{c}\mathbf{3 6} \\
\mathbf{2}\end{array}$ & $\begin{array}{l}\mathbf{3 6} \\
\mathbf{9}\end{array}$ & $\begin{array}{l}\mathbf{3 7} \\
\mathbf{2}\end{array}$ \\
\hline \hline BC & $\mathrm{R}$ & $\mathrm{R}$ & $\mathrm{R}$ & $\mathrm{R}$ & $\mathrm{S}$ & $\mathrm{S}$ & $\mathrm{S}$ & $\mathrm{T}$ & $\mathrm{T}$ & $\mathrm{T}$ \\
\hline PP & $\mathrm{S}$ & $\mathrm{S}$ & $\mathrm{R}$ & $\mathrm{S}$ & $\mathrm{S}$ & $\mathrm{S}$ & $\mathrm{T}$ & $\mathrm{S}$ & $\mathrm{S}$ & $\mathrm{S}$ \\
\hline ANC & $\mathrm{R}$ & $\mathrm{T}$ & $\mathrm{R}$ & $\mathrm{R}$ & $\mathrm{S}$ & $\mathrm{S}$ & $\mathrm{R}$ & $\mathrm{S}$ & $\mathrm{T}$ & $\mathrm{T}$ \\
\hline PNP & $\mathrm{R}$ & $\mathrm{R}$ & $\mathrm{R}$ & $\mathrm{R}$ & $\mathrm{R}$ & $\mathrm{R}$ & $\mathrm{T}$ & $\mathrm{R}$ & $\mathrm{T}$ & $\mathrm{T}$ \\
\hline KRS & $\mathrm{R}$ & $\mathrm{R}$ & $\mathrm{R}$ & $\mathrm{R}$ & $\mathrm{R}$ & $\mathrm{S}$ & $\mathrm{R}$ & $\mathrm{T}$ & $\mathrm{S}$ & $\mathrm{T}$ \\
\hline KER & $\mathrm{R}$ & $\mathrm{R}$ & $\mathrm{S}$ & $\mathrm{R}$ & $\mathrm{R}$ & $\mathrm{S}$ & $\mathrm{R}$ & $\mathrm{S}$ & $\mathrm{S}$ & $\mathrm{S}$ \\
\hline
\end{tabular}

TABEL IIII

FDT HUKUM PIDANA MATERIIL (LANJUTAN)

\begin{tabular}{|c||l|l|l|l|l|l|l|l|l|l|}
\hline Tuntutan & 374 & $\mathbf{3 7 5}$ & $\mathbf{3 6 9}$ & $\mathbf{3 7 2}$ & $\mathbf{3 7 4}$ & $\mathbf{3 7 5}$ & $\mathbf{3 7 8}$ & $\mathbf{4 8 0}$ & $\mathbf{3 6 3}$ & $\mathbf{4 8 1}$ \\
\hline \hline BC & $\mathrm{T}$ & $\mathrm{T}$ & $\mathrm{T}$ & $\mathrm{T}$ & $\mathrm{T}$ & $\mathrm{T}$ & $\mathrm{T}$ & $\mathrm{T}$ & $\mathrm{T}$ & $\mathrm{T}$ \\
\hline PP & $\mathrm{S}$ & $\mathrm{S}$ & $\mathrm{S}$ & $\mathrm{S}$ & $\mathrm{S}$ & $\mathrm{S}$ & $\mathrm{T}$ & $\mathrm{T}$ & $\mathrm{T}$ & $\mathrm{T}$ \\
\hline ANC & $\mathrm{T}$ & $\mathrm{T}$ & $\mathrm{T}$ & $\mathrm{T}$ & $\mathrm{T}$ & $\mathrm{T}$ & $\mathrm{T}$ & $\mathrm{R}$ & $\mathrm{R}$ & $\mathrm{R}$ \\
\hline PNP & $\mathrm{T}$ & $\mathrm{T}$ & $\mathrm{T}$ & $\mathrm{T}$ & $\mathrm{T}$ & $\mathrm{T}$ & $\mathrm{T}$ & $\mathrm{T}$ & $\mathrm{T}$ & $\mathrm{R}$ \\
\hline KRS & $\mathrm{T}$ & $\mathrm{R}$ & $\mathrm{S}$ & $\mathrm{T}$ & $\mathrm{T}$ & $\mathrm{R}$ & $\mathrm{T}$ & $\mathrm{R}$ & $\mathrm{T}$ & $\mathrm{R}$ \\
\hline KER & $\mathrm{T}$ & $\mathrm{R}$ & $\mathrm{S}$ & $\mathrm{S}$ & $\mathrm{T}$ & $\mathrm{R}$ & $\mathrm{R}$ & $\mathrm{R}$ & $\mathrm{T}$ & $\mathrm{R}$ \\
\hline
\end{tabular}

TABEL IIIII

FDT HUKUM PIDANA MATERIIL (LANJUTAN)

\begin{tabular}{|c||c|c|c|c|c|c|}
\hline Tuntutan & 365.1 & $\mathbf{3 6 5 . 2}$ & $\mathbf{3 6 5 . 3}$ & $\mathbf{3 3 8}$ & $\mathbf{3 3 9}$ & $\mathbf{3 4 0}$ \\
\hline \hline BC & $\mathrm{T}$ & $\mathrm{T}$ & $\mathrm{T}$ & $\mathrm{S}$ & $\mathrm{T}$ & $\mathrm{T}$ \\
\hline PP & $\mathrm{S}$ & $\mathrm{S}$ & $\mathrm{S}$ & $\mathrm{S}$ & $\mathrm{T}$ & $\mathrm{T}$ \\
\hline ANC & $\mathrm{S}$ & $\mathrm{T}$ & $\mathrm{T}$ & $\mathrm{T}$ & $\mathrm{T}$ & $\mathrm{T}$ \\
\hline PNP & $\mathrm{T}$ & $\mathrm{R}$ & $\mathrm{S}$ & $\mathrm{R}$ & $\mathrm{S}$ & $\mathrm{T}$ \\
\hline KRS & $\mathrm{R}$ & $\mathrm{T}$ & $\mathrm{T}$ & $\mathrm{T}$ & $\mathrm{T}$ & $\mathrm{T}$ \\
\hline KER & $\mathrm{R}$ & $\mathrm{T}$ & $\mathrm{T}$ & $\mathrm{T}$ & $\mathrm{T}$ & $\mathrm{T}$ \\
\hline
\end{tabular}

\section{고 $\triangle$ \\ \& 1 .nl 2:34 PM}

\section{Pidana}

\section{HUKUM PIDANA PENCURIAN FUZZY DECISION TABLE}

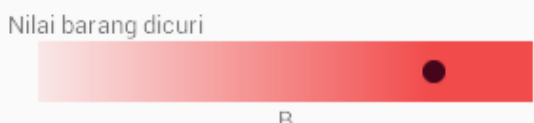

Jumlah pelaku

-

Tingkat Ancaman

Jumlah Pelaku : 0/10

Tingkat Ancaman : 0/10

Tingkat penipuan

Tingkat Penipuan : 0/10

Tingkat kerusakan

○

Gbr. 2 Halaman Aplikasi

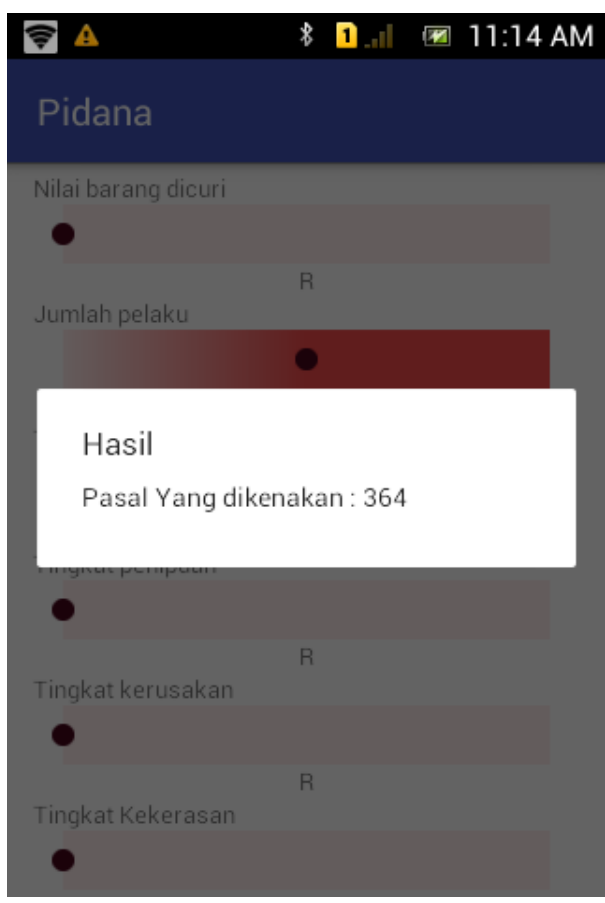

Gbr. 3 Halaman Hasil Konsultasi

\section{B. Pengujian}

Pengujian dilakukan menggunakan dengan menggunakan ekosistem android 4.0 Jely Bean dengan menggunakan widget seekbar untuk memilih tingkat tuntutan dalam menentukan pasal yang dikenakan pada Gbr. 2 posisi ketika aplikasi dalam kondisi belum ditentukan beberapa tuntutannya. 
Selanjutnya pada gbr. 3. Dicoba dipilih beberapa tuntutan berdasarkan kadarnya maka hasil yang di tampilkan muncul pada toast message.

\section{KESIMPULAN}

Kesimpulan Penelitian yang telah dilakukan bahwa Aplikasi dapat berjalan dengan baik, dapat memilah pasalpasal pidana sesuai dengan pilihan pengguna dan dapat digunakan sebagai referensi konsultasi kasus hukum, khusus kasus pencurian.

\section{UCAPAN TERIMA KASIH}

Terima kasih kami sampaikan kepada editor \& reviewer yang telah meluangkan waktu untuk memeriksa dan memberikan masukan sertakoreksi pada paper ini..

\section{REFERENSI}

[1] Andreas Handojo, Fendhy Ongko, and M. Isa Irawan, "PERANCANGAN DAN PEMBUATAN APLIKASI SISTEM PAKAR UNTUK PERMASALAHAN TINDAK PIDANA TERHADAP HARTA KEKAYAAN," Jurnal Informatika, vol. 5, no. 1, pp. 32-38, Mei 2004.

[2] Ahmad Bahiej, "Sejarah dan Problematika Hukum Pidana Materiel di Indonesia," SOSIO-RELIGIA, vol. 4, no. 4, pp. 1-20, Februari 2006.

[3] Agus Raharjo, "Problematika Asas Retroaktif dalam Hukum Pidana Indonesia," Jurnal Dinamika hukum, vol. 8, no. 1, pp. 70-80, Januari 2008.

[4] Roni Wiyanto, Asas-Asas Hukum Pidana Indonesia. Bandung, Indonesia/Jawa Barat: Mandar Maju, 2012.

[5] Bag. Ren., "Laporan Akuntabilitas Kinerja Instansi Pemerintah (LAKIP) Sukabumi," Kepolisian Resor, Sukabumi Kota, Annual 2013.

[6] Sat Reskrim, "Laporan Tahunan Kriminal Sat Reskrim," Kepolisian Rsor, Sukabumi Kota, Annual 2013.

[7] Wahyu Ardianto, Wiwik Anggraeni, and Ahmad Mukhlason, "Pembuatan Sistem Pakar Untuk Pendeteksian dan Penanganan Dini
Pada Penyakit Sapi Berbasis Mobile Android Dengan Kajian Kinerja Teknik Knowledge Representation," Jurnal Teknik ITS, vol. 1, no. 1, pp. 310-315, Jan. 2012.

[8] Hersatoto Listiyono, "Merancang dan Membuat Sistem Pakar," Dinamik - Jurnal Teknologi Informasi, vol. 13, no. 2, pp. 115-124, Juli 2008.

[9] Nina Sevani, Marimin Marimin, and Heru Sukoco, "SISTEM PAKAR PENENTUAN KESESUAIAN LAHAN BERDASARKAN FAKTOR PENGHAMBAT TERBESAR (MAXIMUM LIMITATION FACTOR) UNTUK TANAMAN PANGAN," Jurnal Informatika, vol. 10, no. 1, pp. 23-31, Mei 2009.

[10] Meilany Nonsi Tentua, "SISTEM PAKAR UNTUK IDENTIFIKASI KEJAHATAN DUNIA MAYA," Jurnal Dinamika Informatika, vol. 4, no. 1, pp. 1-9, Februari 2010

[11] Muhammad Ichwan, Milda Gustiana Husada, and M. Iqbal Ar Rasyid, "PEMBANGUNAN PROTOTIPE SISTEM," Jurnal INFORMATIKA, vol. 4, no. 1, pp. 13-25, Januari 2013.

[12] Nardi Nardi and Nazori A Z, "OTOMASI KLASIFIKASI AWAN CITRA SATELIT MTSAT ," Telematika MKOM, vol. 4, no. 1, pp. 104-117, Maret 2012

[13] Jogiyanto Hartono Mustakini, Analisa dan Desain Sistem Informasi: Pendekatan. Terstruktur Teori dan Praktik Aplikasi Bisnis. Yogyakarta, Indonesia: ANDI, 2005.

[14] Frank J.A. WITLOX, Aloys W.J. BORGERS, and Harry J.P. TIMMERMANS. (2004) [Online]. https://deepblue.lib.umich.edu/bitstream/handle/2027.42/60302/Wit oxEdited.PDF? sequence $=1 \&$ isAllowed $=y$

[15] Guoqing CHEN. [Online]. http://int.polytech.univsmb.fr/fileadmin/polytech_autres_sites/sites/listic/busefal/Papers/63. zip/63 14.pdf

[16] Boy Fechera, Jaja Kustija, and Siscka Elvyanti, "OPTIMASI PENGGUNAAN MEMBERSHIP FUNCTION LOGIKA FUZZY PADA KASUS IDENTIFIKASI KUALITAS MINYAK TRANSFORMATOR," ELEKTRANS, vol. 11, no. 2, pp. 27-35, September 2012.

[17] Martinus Maslim, "APLIKASI LOGIKA ," in SENTIKA, Yogyakarta, 2013, pp. 112-119. 